\title{
Mediación artística. Intervención social a través del arte y la cultura en Honduras
}

\section{Art mediation. Social intervention through art and culture in Honduras}

\section{Mediação artística. Intervenção social através da arte e da cultura em Honduras}

\author{
LIDIA S. CÁLIX VALLECILLO | lidia.calix@unah.edu.hn \\ UNIVERSIDAD NACIONAL AUTÓNOMA DE HONDURAS | HONDURAS
}

Received · Recibido · Recebido : 2 de enero de 2020 | Accepted · Aceptado · Aceito: 13 de marzo de 2020 DOI: https://dx.doi.org/10.12795/Communiars.2020.i03.01

(c) (1) (2) Artículo bajo licencia Creative Commons BY-NC-SA

How to cite this article · Cómo citar este artículo · Como citar este artigo:

Vallecillo, L. (2020). Mediación artística. Intervención social a través del arte y la cultura en Honduras. Communiars. Revista de Imagen, Artes y Educacion Crítica y Social,2, 22-30.

\section{Resumen:}

Honduras es un país inseguro, corrupto y subdesarrollado. La situación de riesgo y vulnerabilidad social permanente son situaciones ineludibles de intervención perentoria. Las disciplinas artísticas y enfoques socioeducativos que apuntan hacia el desarrollo cultural y comunitario son alcanzados por la mediación artística.

Hacer cultura contra la barbarie es el sentido más palpable en varios de los proyectos de mediación artística realizados por organizaciones independientes, internacionales y estatales en el país.

La UNAH (Universidad Nacional Autonoma de Honduras), en tanto rectora de la educación superior en Honduras, ha desarrollado durante 5 años, desde el 2015, el diplomado de Enseñanza de las Artes Visuales en Contextos de riesgo de Exclusión Social. Tal formación ha sido creada bajo la colaboración bilateral de Honduras y España y se materializa en la formación en la educación artística más actual del mundo global; no obstante, haciendo énfasis en la Metodología Artísticas de Enseñanza (MAE) en contextos de alta vulnerabilidad social. Con las MAE y el arte visual contemporáneo hondureño se 
cumplen dos aspectos fundamentales: la aplicación del precepto metodológico y el reconocimiento de la fortaleza de contar con artistas que ejercen un papel crítico y constructivo.

Los logros alcanzados demuestran que la formación recibida ha afectado positivamente a la promoción del arte hondureño, a los participantes, y a las zonas prioritarias elegidas.

Palabras claves: Honduras. Arte contemporáneo. Mediación artística. Exclusión social. Educación artística. Vinculación con la sociedad.

\section{Abstract:}

Honduras is an insecure, corrupt and underdeveloped country. The situation of risk and permanent social vulnerability are unavoidable situations of peremptory intervention. The artistic disciplines and socioeducational approaches that point towards cultural and community development are achieved by art mediation.

Making culture against barbarism is the most palpable sense in several of the art mediation projects carried out by independent, international and state organizations in the country.

UNAH (Universidad Nacional Autonoma de Honduras), as the rector of higher education in Honduras, has developed for 5 years, since 2015, the diploma course of Teaching of the Visual Arts in Contexts of risk of Social Exclusion. Such training has been created under the bilateral collaboration of Honduras and Spain and is embodied in the most current artistic education training in the global world; however, emphasizing the Artistic Teaching Methodology (MAE) in contexts of high social vulnerability. With the MAE and contemporary Honduran visual art, two fundamental aspects are fulfilled: the application of the methodological precept and the recognition of the strength of having artists who play a critical and constructive role.

The achievements achieved show that the training received has positively affected the promotion of Honduran art, the participants, and the priority areas chosen.

Keywords: Honduras. Contemporary art. Art mediation. Social exclusion. Art education. Relationship with society.

\section{Resumo:}

Honduras é um país inseguro, corrupto e subdesenvolvido. A situação de risco e a vulnerabilidade social permanente são situações inevitáveis de intervenção peremptória. As disciplinas artísticas e as abordagens socioeducacionais que apontam para o desenvolvimento cultural e comunitário são alcançadas pela mediação artística.

Tornar a cultura contra a barbárie é o sentido mais palpável em vários dos projetos de mediação artística realizados por organizações independentes, internacionais e estatais no país.

A UNAH (Universidad Nacional Autónoma de Honduras), como reitora do ensino superior em Honduras, desenvolve há 5 anos, desde 2015, o diploma de Ensino de Artes Visuais em Contextos de Risco de Exclusão Social. Esse treinamento foi criado sob a colaboração bilateral de Honduras e Espanha e está incorporado no mais atual treinamento em educação artística do mundo global; no entanto, enfatizando a Metodologia do Ensino Artístico (MAE) em contextos de alta vulnerabilidade social. Com o MAE e a arte visual contemporânea de Honduras, dois aspectos fundamentais são cumpridos: a aplicação do preceito metodológico e o reconhecimento da força de ter artistas que desempenham um papel crítico e construtivo.

As realizações alcançadas mostram que o treinamento recebido afetou positivamente a promoção da arte hondurenha, os participantes e as áreas prioritárias escolhidas. 
Palavras-chave: Honduras. Arte contemporânea. Mediação artística. Exclusão social. Educação artística. Relacionamento com a sociedade.

No acepten lo habitual como cosa natural... nada debe parecer natural, nada debe parecer imposible de cambiar.

Bertold Brecht

\section{Honduras: un país susceptible de intervención socio-artística}

El videoclip musical "Así te amo yo, Honduras" muestra parte de la riqueza natural y cultural del país... Sin embargo, no todo es tan paradisíaco cuando se constata que, en el índice de Paz Global 2017, Honduras ocupa la no honrosa posición 106 de 163 países estudiados, el penúltimo puesto en lo que refiere al desarrollo en Latinoamérica, solamente debajo de Haití según el Informe 2016 del Programa de las Naciones Unidas para el Desarrollo (PNUD); la percepción de la corrupción del sector público es muy alta (puesto 135 de 180) según reporta el Informe de Transparencia Internacional 2017; sin olvidar que la oenegé Global Witness advierte que es un país sumamente peligroso para los defensores del ambiente (123 ecologistas han sido asesinados desde 2010).

Berta Cáceres es parte de esa nefasta circunstancia. Ella, líder indígena, feminista, lenca, defensora del ambiente y ganadora del premio Goldman, fue asesinada por defender la vida: el río Gualcarque, agua vital que pertenece ancestralmente a la comunidad lenca, de tal modo que enfrentó a poderosas empresas multinacionales, grupos de poder e intereses partidistas que violentaron el Convenio 169 suscrito con la Organización Internacional del Trabajo (OIT) sobre los derechos de los pueblos indígenas.

Existen estudios que relacionan la pobreza fundamentalmente con el acceso al empleo digno, a la educación, la salud y la seguridad. No tener una fuente de ingresos genera inseguridad, incentiva la migración ilegal e incrementa los niveles de violencia.

Honduras tiene un $68.8 \%$ de población viviendo en condición de pobreza del cual, el $24.7 \%$ corresponde a la pobreza relativa y el $44.2 \%$ a la pobreza extrema (Foro Nacional de la Deuda Externa [FOSDEH], basándose en datos del Instituto Nacional de Estadística [INE] de 2017). Posee una tasa de 6.7 de desocupados y 55.1 de ocupados. Con relación a esta última cifra, y según el INE, el 50\% está subempleada (Hasta el primer semestre de 2017, según Informe de la OIT.). Un $11 \%$ de su población, de 9,265 millones, no sabe leer ni escribir y se ubica sobretodo en el área rural. La tasa de cobertura educativa preuniversitaria en el ámbito nacional es de $59.8 \%$ y la universitaria $16.2 \%$.

Según el informe 2011 de la Junta internacional de Fiscalización de Estupefacientes (JIFE) de la Organización de las Naciones Unidas (ONU), la pobreza, la desigualdad social, la ausencia de oportunidades económicas y la emigración han permitido que el narcotráfico prospere en la región. Por Centroamérica transita el $90 \%$ de la droga que llega a Estados Unidos de América; y en esto representa el 13\% del PIB de Honduras; específicamente la cocaína: mil novecientos cincuenta millones de dólares. Aunque hay pocos estudios que correlacionan el incremento de la violencia con el narcotráfico, el 70.4\% de homicidios en Honduras, incluidos 
en las 7,027 muertes por causa externa del 2017, son causados con arma de fuego y la posible causa, más común, es por ajuste de cuentas . La tasa de homicidios es de 43.6 pcmh y la media en el mundo está en 5.3. En el año 2014 fue considerado el país sin conflicto bélico con la tasa de homicidios más alta en el mundo.

La mirada del "otro" no es la misma cuando se habla de migrantes hondureños o de otros países en vías de desarrollo. Para el caso, Donald Trump dijo: "...All these people from shithole countries...here?". Según cifras oficiales, en todo 2017 Estados Unidos deportó a 198 menores hondureños, mientras que 4474 retornaron desde México, 58 fueron expulsados desde países centroamericanos y otros 6 de países de Europa y Sudamérica. En una reciente encuesta realizada por la Universidad de Costa Rica cuya pregunta fundamental fue: "¿Migrarían?", el $60 \%$ de los hondureños encuestados dijo que sí. Recientemente, hemos sido testigos de las caravanas de migrantes centroamericanos que aún se mantienen en el foco de atención de los medios internacionales. Estas caravanas son particulares ya que su modalidad de tránsito está despojada del ocultamiento que le había sido característico.

Con relación al acceso a la salud pública, hay que mencionar el caso emblemático de corrupción relacionado con el Instituto Hondureño de Seguridad Social: el desfalco que se estima fue de 7 mil millones de lempiras. Refiriéndose a ese latrocinio, en La Nación del miércoles 3 de junio de 2015 aparece el artículo titulado "Admite presidente hondureño desvío de fondos públicos para su partido". Ante esta declaración, el movimiento social de la oposición indignada a través de la marcha de las Antorchas manifestó su hartazgo en innumerables ocasiones solicitando a la ONU la Comisión Internacional Contra la Impunidad en Honduras (CICIH). No logró la CICIH sino la Misión de Apoyo contra la Corrupción y la Impunidad en Honduras (MACCIH), quien a finales de 2017, un año después de estar operando en el país, denunció el "Pacto de Impunidad" que se instauró en el Congreso Nacional al reformar la Ley Orgánica del Presupuesto, legislación que fomenta la impunidad al proteger a funcionarios y exfuncionarios corruptos.

Recientemente, el 19 de enero de 2020 para ser precisos, la MACCIH no siguió funcionando en el país dado que el gobierno de Juan Orlando Hernández no renovó el convenio.

Otro caso que concierne al Estado y que violenta la incipiente democracia de Honduras son las elecciones presidenciales del 2017, pues fuertes indicios colocan al actual presidente de Honduras, Juan Orlando Hernández Alvarado, como un usurpador del poder. Los antecedentes clave para la instauración del actual gobierno son: el Golpe técnico a la Corte Suprema de Justicia, que significó la defenestración de cuatro magistrados de la Sala de lo Constitucional por el Congreso Nacional de la República, la desaparición con alevosía del Partido Nacional Anticorrupción, el fortalecimiento del presupuesto de seguridad y defensa y, posterior al acto, el respaldo de Estados Unidos de Norteamérica, dejando entrever los intereses geopolíticos en la región.

Del presupuesto 2018 publicado en el diario oficial La Gaceta destacaría que el monto de seguridad y defensa es mayor que el asignado a salud. Según FOSDEH, llegamos a un aproximado de 15,000 millones de dólares de endeudamiento, un 70\% del PIB teniendo como principal asignación presupuestaria el pago de intereses y capital de deuda y no para inversión. 
Datos de las prácticas y hábitos culturales en Honduras identificados por la macroencuesta de la Organización de Estados Iberoamericanos (OEI) de 2013 revelan que más del 80\% de la población no tiene acceso al teatro, conciertos y parques históricos o culturales. El estudio hace hincapié en que las políticas públicas deben contribuir a suprimir las barreras que genera esta distancia, y a multiplicar su oferta hacia colectivos para facilitar su acceso y participación en las actividades culturales. Sin embargo, en Honduras no existe una política cultural aunque se han tenido diferentes intentos promovidos por diferentes gremios.

Hay muchos más aspectos del panorama nacional qué mencionar, pero en resumen se puede señalar que la violencia sistémica, oculta, indirecta o institucional o estructural es evidente. Al escoger como alternativa la intervención social es preciso tener claro el contexto socio económico político y cultural del colectivo que podemos abordar a través del arte y la cultura, su condición de excluidos o en riesgo de exclusión y la aspiración: la inclusión social.

\section{Según Moreno González:}

La exclusión social es de origen estructural, tiene carácter multidimensional y es de naturaleza procesual y dinámica; es un proceso social de pérdida de integración que incluye no solo la falta de ingresos y el alejamiento del mercado de trabajo, sino también un debilitamiento de los lazos sociales, un descenso de la participación social y, por tanto, una pérdida de derechos sociales (Fundación Foessa, 2008).

La inclusión social implica, por tanto, el ejercicio efectivo de los derechos: el acceso al empleo, la vivienda, la salud, la educación; pero también a la información, las redes de soporte y relación.

En Honduras existen instituciones gubernamentales que ejercen acciones enfocadas a grupos vulnerables pero no hay una que ejerza el rol rector de la política social. Sin embargo existen proyectos de mediación artística realizados por organizaciones independientes $\mathrm{e}$ internacionales con claros objetivos y productos de inclusión. Antes de exponer varios de sus formatos y tipos de intervención y de centrarse en la descripción de un caso socioeducativo en particular es preciso conocer las fortalezas que en el ámbito de las artes visuales tiene el país. Lo es, puesto que la metodología enfoque del proyecto socioeducativo en el cual se centra este artículo se basa fundamentalmente en el arte contemporáneo.

\section{El arte contemporáneo en Honduras de visión sociocrítica}

Honduras posee artistas que se mueven entre el artivismo, el desarrollo cultural comunitario y los procesos formativos. A continuación algunos ejemplares.

1. Años atrás del doloroso asesinato de Berta Cáceres, el artista visual Gabriel Galeano presentó su obra Nubes para ser resguardadas (Figura 1). Una pieza conceptual que discursa sobre la paradoja del agua, un recurso vital que debería ser de acceso para todos, pero que es resguardado en tanto mercancía, generando desigualdad social. 
3. Nora Buchanan creó la instalación en espacio público Regreso a las seis; obra que le dio utilidad al polémico Trans 450, al instalar cruces blancas en memoria de víctimas de la criminalidad e inseguridad en el país.

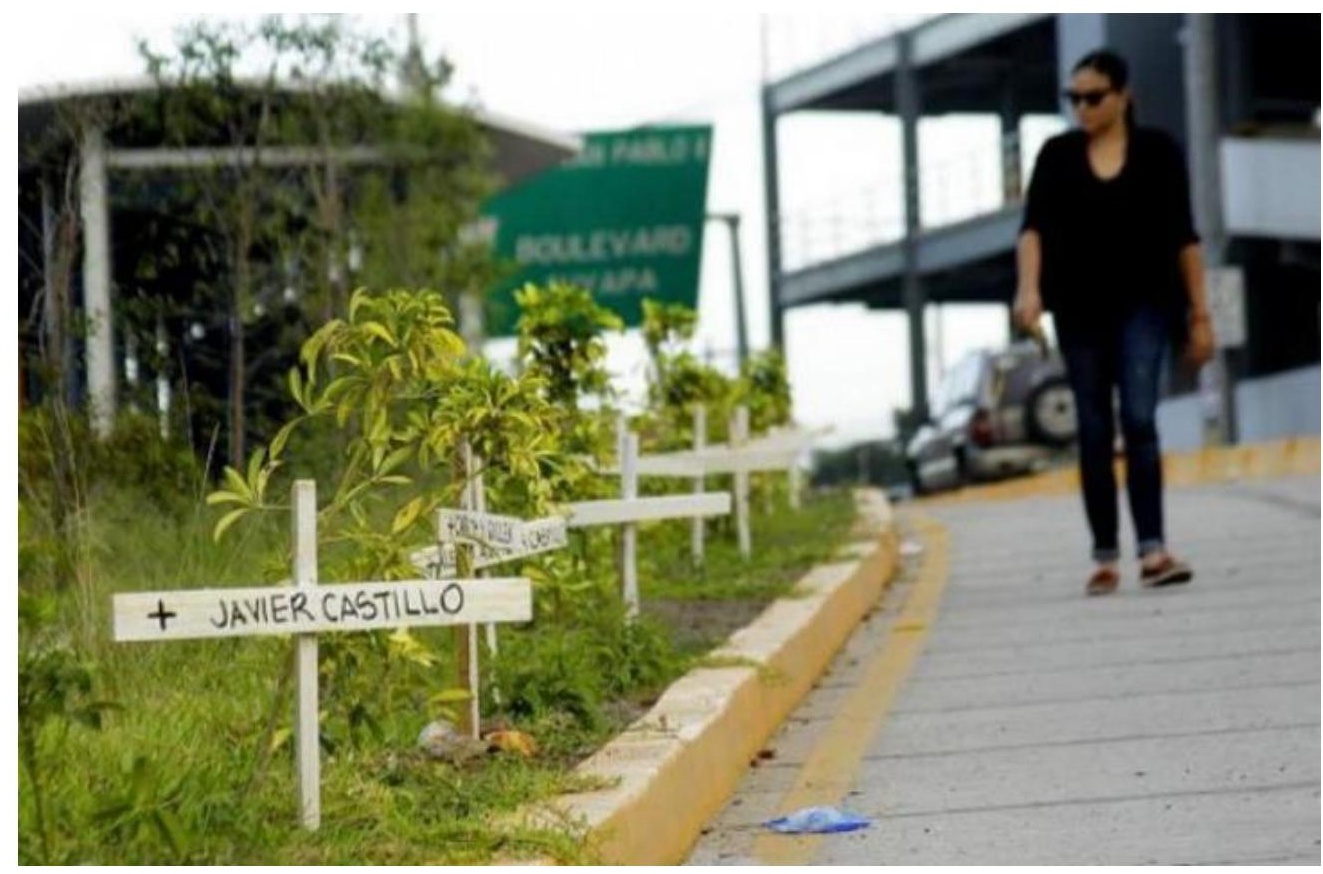

Figura 3. Regreso a las seis, de Nora Buchanan. [Fotografía de Presencia Universitaria]. (Trans 450, Tegucigalpa, 2014). Archivos fotográficos de Presencia Universitaria.

4. El comentario social de la realidad en sí es la fuente de inspiración de Federico Rosa Suazo cuando presenta Honduras bajo el suelo (Figura 4), en el Museo de la Identidad Nacional (MIN), 2017.

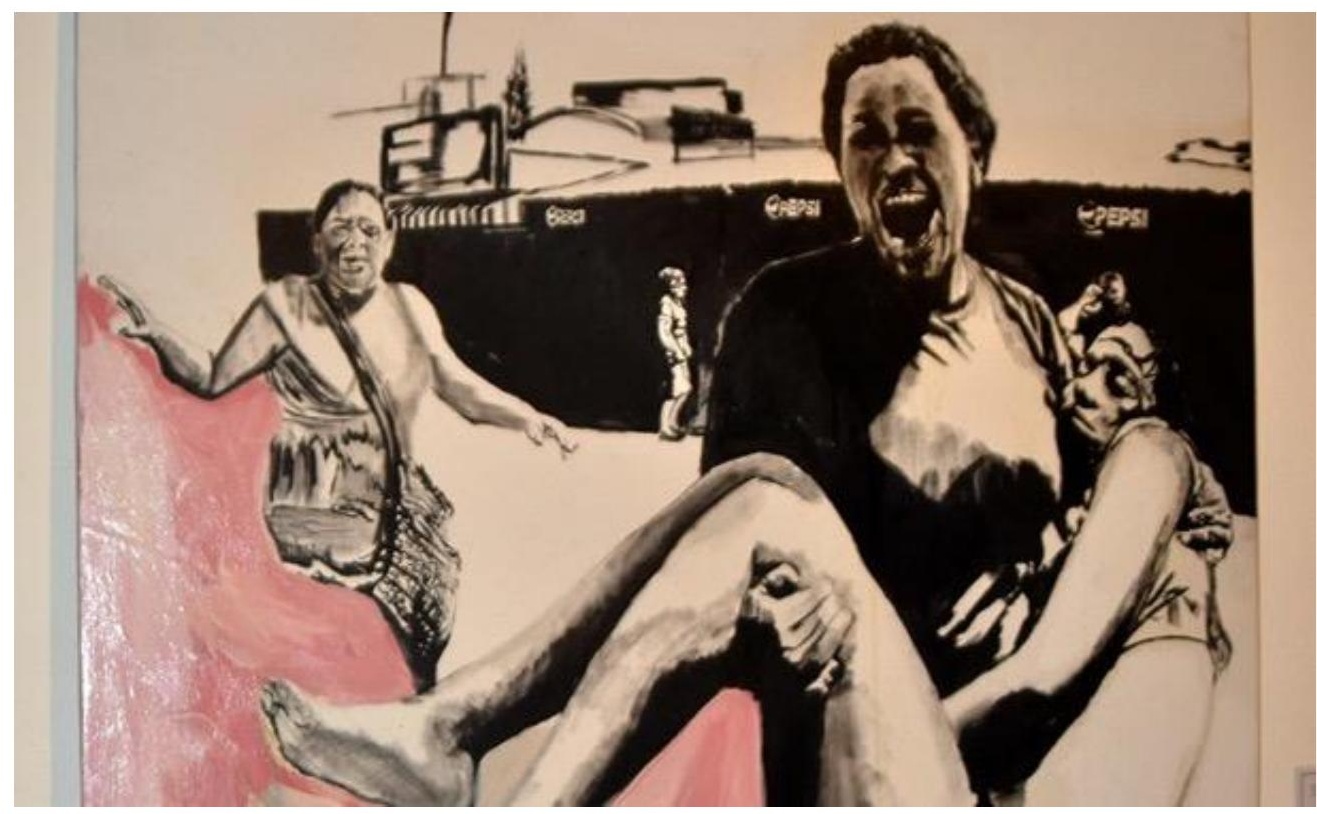


Figura 4. Honduras Bajo el Suelo, de Federico Rosa Suazo. [Fotografía de Federico Rosa Suazo]. (Museo de la Identidad Nacional, Tegucigalpa, 2017). Archivos fotográficos propios.

5. Jorge Oquelí emplea su cuerpo como objeto y sujeto en su performance Honduras. Alegoría de un país que no pudo ser (Figura 5), atónita estampa de la espera, en espera de algo que no existe.

Figura 5. Alegoría de un país que no pudo ser, de Jorge Oquelí. [Fotografía de ars504.com]. (Galería Nacional de Arte, Tegucigalpa, 2010). Archivos fotográficos ars504.com. De la colección de la III bienal de Honduras. 
6. En Autopoiesis I (Figura 6), Adán Vallecillo discursa sobre los dispositivos tecnológicos y culturales que aceleran el crecimiento de los niños, sometiendo sus cuerpos y espíritus a situaciones de explotación y que los priva de un desarrollo físico, psíquico y emocional saludable.

Figura 6. Autopoiesis I, de Adán Vallecillo. [Fotografía de Adán Vallecillo]. (Museo para la Identidad Nacional, Tegucigalpa, 2008). Archivos fotográficos del autor.

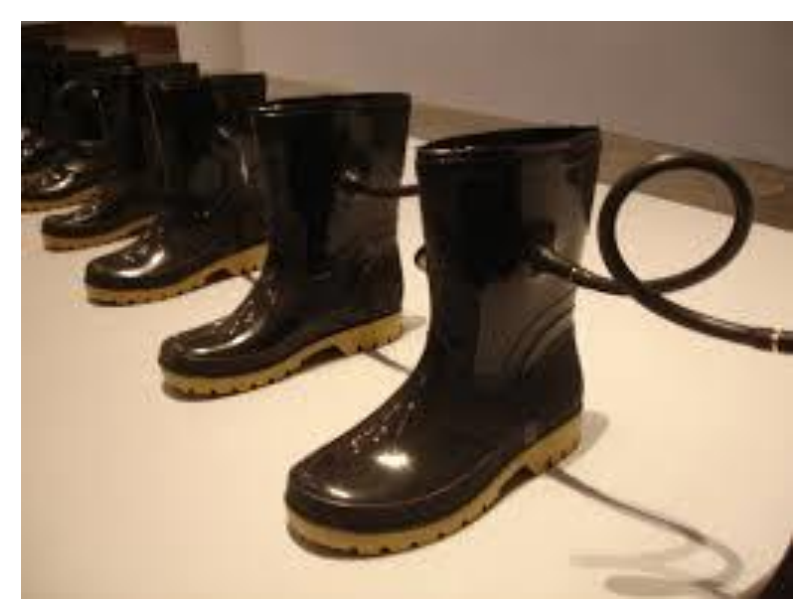

7. Asepsiófono (Figura 7), de Adán Vallecillo, evidencia algunas fuerzas de poder mediante categorizaciones simbólicas en las que combina aproximaciones objetuales y condiciones subjetivas e históricas específicas, como, por ejemplo, las relaciones entre la parafernalia de la paranoia (objetos, mecanismos y estrategias de seguridad) y la democracia representativa actual.

Figura 7. [Fotografía de Adán Vallecillo]. (Tegucigalpa, 2005). Archivos fotográficos del autor. Asepsiófono, de Adán Vallecillo.

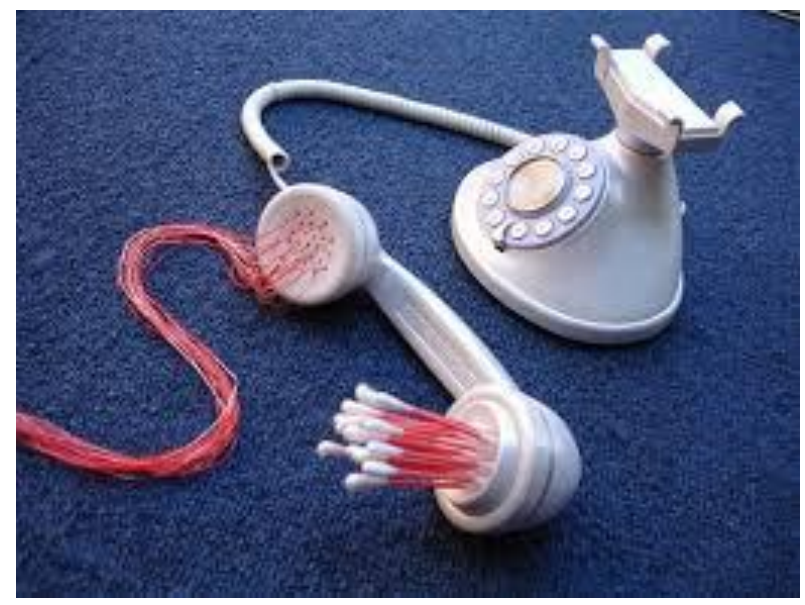


8. Perdidos, pero tomados de la mano (Figura 8), es una obra de mi autoría que representa esa condición de estar en el mundo, quizás sin la certeza de saber cuál es la verdad o el destino pero estando unidos. Esa unidad en medio de la tragedia proviene del conocimiento procomún, algo que puede lograrse a través del arte y la cultura.

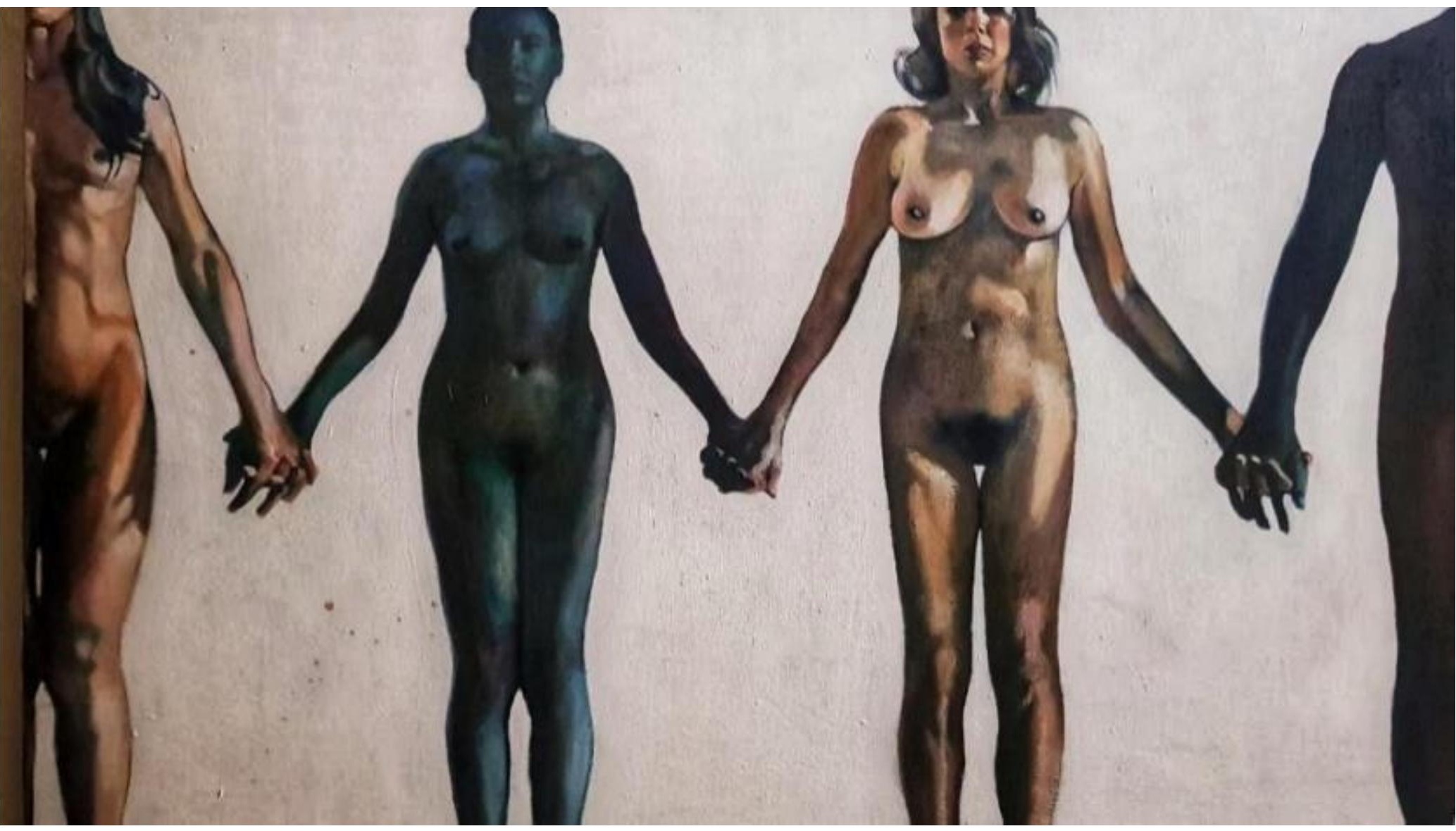

Figura 8. Perdidos pero tomados de la mano, de Lidia Cálix. [Fotografía de Lidia Cálix] ]. (Tegucigalpa, 2005). Archivos fotográficos propios.

Otros artistas contemporáneos que intervienen en espacios públicos son:

1. Romina Memoli

2. César Manzanares 


\section{Mapeo de mediaciones artísticas en Honduras}

Elliot Eisner (1995) opinaba que había dos tipos de justificaciones para la enseñanza del arte: una esencialista y otra contextualista. Fusionar ambas en la mediación artística no es un reto fácil pero sí urgente y coherente, en respuesta al panorama nacional.

Para mediar artísticamente se debe iniciar por investigar los procesos de exclusión y sus "causas" ( de las personas en situación de riesgo o vulnerabilidad social y las personas en situación de exclusión social ${ }^{1}$ ), para luego elegir los tipos o ámbitos de intervención y la inclusión desde las diferentes disciplinas artísticas y enfoques (terapéutico, socioeducativo, desarrollo cultural comunitario, económico, expresivo en derechos, participación política, etcétera). De allí, determinar las características que habrían de tener las iniciativas a impulsar.

Para construir estrategias de inclusión se puede tomar en cuenta: a) el espacio de la producción, del mercado de trabajo y del consumo; b) el espacio de la ciudadanía; y c) el espacio relacional y de los vínculos sociales. Los proyectos artísticos inciden en cada uno de estos espacios: el arte genera ocupación y empleo, constituye un espacio de participación social y de transformación a través de la toma de conciencia, la denuncia y propuesta de alternativas; deconstruye prejuicios y estigmas (indicadores de discriminación), y fortalece la autoestima, la identidad y la historia.

En Honduras se han intervenido socialmente ciertos ámbitos, a través de varios sectores que se ven en el siguiente diagrama.

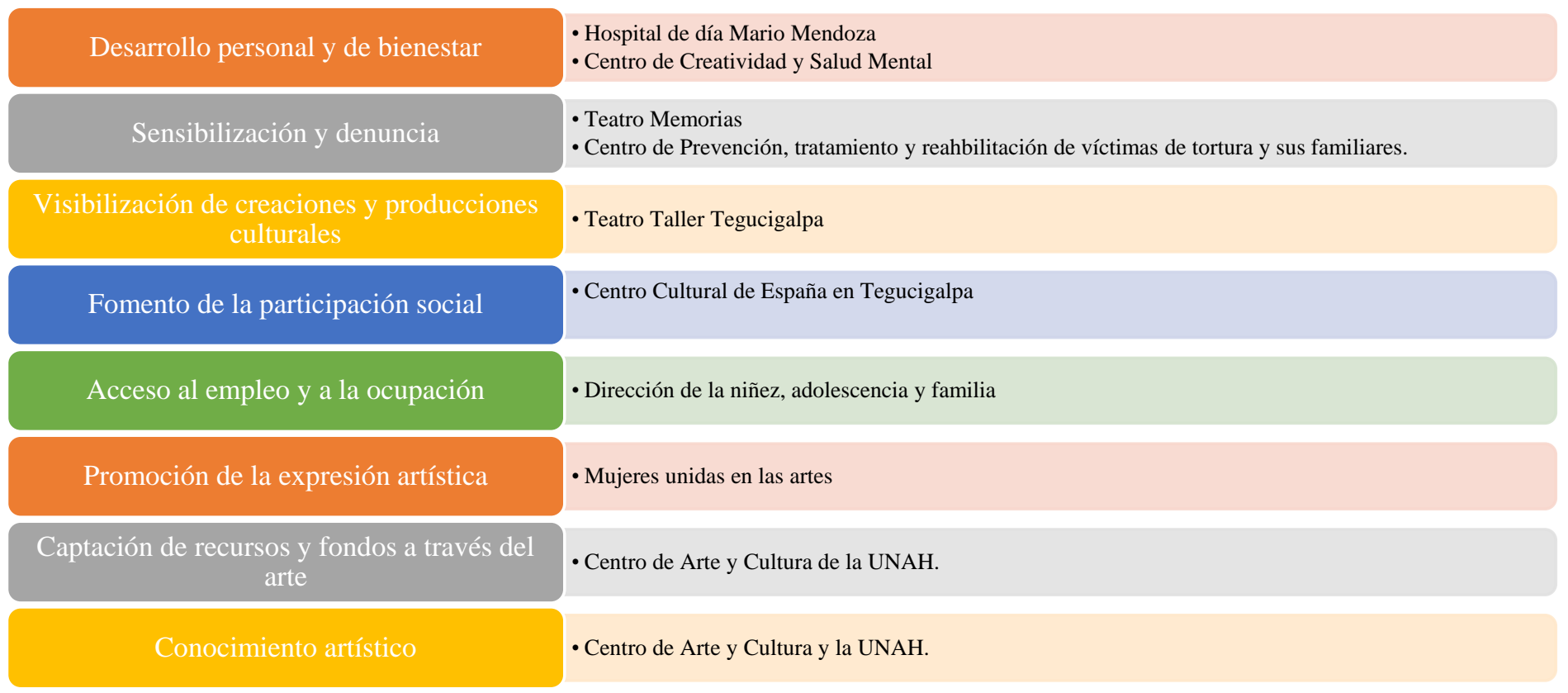

\footnotetext{
${ }^{1}$ Las primeras afrontan situaciones de riesgo de exclusión, como el empleo precario o inestable o el fracaso escolar; además, debido a su sexo, edad, origen y/o etnia, nivel de autonomía, cuentan con mayores posibilidades de afrontar situaciones de riesgo o exclusión. Las segundas afrontan situaciones objetivas de exclusión tales como el desempleo, la falta de escolarización, entre otras.
} 
Asimismo se pueden visualizar en la red distintos vídeos y páginas de proyectos muy diversos e interesantes, tales como:

- Museo del Prado en Tegucigalpa. Proyecto del Centro Cultural de España en Tegucigalpa: https://www.youtube.com/watch?v=Akfjca-A_C8

- Pi Art a través de la Casa del Jazz Hn: https://www.facebook.com/lacasadeljazzhn/

- Teatro del Oprimido: https://www.youtube.com/watch?v=f3k0PA5dmBw

- El Generalito, obra de Teatro Memorias: https://www.youtube.com/watch?v=8tJDt1k8jNM

\subsection{Un caso de mediación artística socioeducativa: El diplomado Enseñanza de las Artes Visuales (EAV) en contextos de riesgo de exclusión social}

El Diplomado EAV se construye entre profesionales de la Universidad Nacional Autónoma de Honduras (UNAH) y la Universidad de Granada (UGR), España, cuyo actor de preámbulo es la Asociación Cooperación y Esfuerzo (ACOES). Esta fundación, sin fines de lucro y dirigida por el Padre Patricio de la Rosa, interviene desde hace varios años en zonas de riesgo y exclusión social en varios departamentos del país. Aquí es donde la UGR incia su recorrido al plantear el proyecto Arte para aprender en Honduras "Bombearte".

Por un lado se tiene a la UGR y su proyecto llevado a ACOES a través del I+D+i y por el otro, a la UNAH quien tiene el mandato constitucional de rectorar la Educación Superior, promover la cultura y estudiar los problemas nacionales.

La UNAH, en su Plan Estratégico institucional posee dos dimensiones estrechamente ligadas a la justificación del proyecto de Diplomado EAV: Vinculación con la sociedad y Lo esencial de la Reforma Universitaria. La Facultad de Humanidades y Artes es la que, mediante su Plan Operativo Anual, y el encuentro intererinstitucional acoge la creación y gestión del Diplomado formulado en el 2014. Este proyecto de formación continua y no formal tiene un total de 14 módulos (Tabla 1).

Tabla 1: Módulos Diplomado Enseñanza de las Artes Visuales en contextos de riesgo de exclusión social. Fuente: Elaboración propia.

\begin{tabular}{|l|l|}
\hline UNIDAD & MÓDULOS \\
\hline $\begin{array}{l}\text { FORMACIÓN EN ARTES VISUALES (12 horas } \\
\text { presenciales, conferencias online y presenciales) }\end{array}$ & Módulo 1: Experiencia estética \\
\cline { 2 - 2 } & $\begin{array}{l}\text { Módulo 2: Principios fundamentales del diseño de } \\
\text { imágenes y del lenguaje visual. }\end{array}$ \\
\cline { 2 - 2 } & $\begin{array}{l}\text { Módulo 3: El arte contemporáneo en Honduras, referente } \\
\text { para la educación artística visual. }\end{array}$ \\
\hline & Módulo 4: Teorías previas sobre educación artística \\
\hline
\end{tabular}




\begin{tabular}{|c|c|}
\hline \multirow{2}{*}{$\begin{array}{l}\text { CONCEPTOS Y TEORÍAS PEDAGÓGICAS } \\
\text { SOBRE LA EDUCACIÓN ARTISTICA (8 horas } \\
\text { presenciales en UNAH) }\end{array}$} & $\begin{array}{l}\text { Módulo 5: Historia y paradigmas fundamentales en } \\
\text { Educación Artística contemporánea. }\end{array}$ \\
\hline & $\begin{array}{l}\text { Módulo 6: Legislación educativa hondureña respecto de la } \\
\text { educación artística visual. }\end{array}$ \\
\hline \multirow[t]{2}{*}{$\begin{array}{l}\text { CONTENIDOS Y PROCEDIMIENTOS DE } \\
\text { EDUCACIÓN ARTÍSTICA ( } 8 \text { horas presenciales } \\
\text { en UNAH) }\end{array}$} & Módulo 7: Artes, patrimonio y cultura visual. \\
\hline & $\begin{array}{l}\text { Módulo 8: El dibujo infantil en el contexto educativo } \\
\text { contemporáneo. }\end{array}$ \\
\hline \multirow{3}{*}{$\begin{array}{l}\text { MÉTODOS DE ENSEÑANZA BASADOS EN LAS } \\
\text { ARTES VISUALES ( } 8 \text { horas presenciales en } \\
\text { UNAH) }\end{array}$} & $\begin{array}{l}\text { Módulo 9: Modelos metodológicos de enseñanza basados } \\
\text { en las artes. }\end{array}$ \\
\hline & $\begin{array}{l}\text { Módulo 10: Modelos metodológicos de enseñanza basados } \\
\text { en imágenes. }\end{array}$ \\
\hline & Módulo 11: Educación inclusiva y Artes Visuales. \\
\hline \multirow{2}{*}{$\begin{array}{l}\text { PRÁCTICAS TUTORIZADAS EN CENTROS y } \\
\text { EVALUACION. ( } 22 \text { horas presenciales en Centros } \\
\text { escolares y UNAH) }\end{array}$} & Módulo 12: Prácticas tutorizadas en centros educativos. \\
\hline & Módulo 13: Evaluación de trabajos \\
\hline $\begin{array}{l}\text { TRABAJO AUTONOMO (28 horas no } \\
\text { presenciales)Tutorización online }\end{array}$ & Módulo 14: Trabajo Autónomo \\
\hline
\end{tabular}

El Centro de Arte y Cultura (CAC) de la UNAH, un Proyecto de intervención cultural en zonas de riesgo de exclusión social (Comayagüela) se convierte en el canal decisivo para iniciar el primer año de ejecución con las prácticas artísticas del diplomado en los centros educativos aledaños.

Los argumentos fundamentales para ejecutar el diplomado son tomados del actual el Sistema Educativo Nacional donde el análisis del Currículo Nacional Basico (CNB) muestra que éste deja sin tratar la mayoría de los contenidos, objetivos y competencias relacionadas con las artes visuales y su aprendizaje considerados relevantes en los últimos 20 años.

Las líneas básicas en las que se articula la propuesta curricular respecto del área de educación visual y plástica son: la autoexpresiva (teoría adoptada a raíz de las investigaciones de Viktor Lowenfeld (1947) en los Estados Unidos de América en la década de los cincuenta del siglo XX) y la comunicativa (perspectiva que se adopta en educación visual por influencia de los estudios semióticos sobre el lenguaje, fundamentalmente en los años setenta del siglo pasado).

En el CNB las artes "plásticas" comparten su tiempo de tres horas semanales con las disciplinas: música, teatro y artes y cultura. Las cuatro conforman el bloque de educación artística dentro del área de comunicación.

En Honduras existe la Escuela Nacional de Bellas Artes, única en el país en el grado preuniversitario y un pregrado de profesor de arte de la Universidad Pedagógica Nacional Francisco Morazán. 
La ya desparecida Secretaría de Cultura, Artes y Deportes, actualmente convertida en una simple dirección, se forjó en detrimento de las Casas de la Cultura encargadas de ofertar la educación no formal artística, decreciendo su cobertura.

En Honduras son muy pocos los centros museísticos para la promoción del arte y la cultura. Existe nuevo marco jurídico de la educación artística en la Ley fundamental de Educación y sus reglamentos, sin embargo, es necesario que la Secretaría de Educación implemente la actualización del profesorado, el fortalecimiento de la Educación no formal de las artes y que el máximo órgano del sistema, el Consejo Nacional de Educación, organice el sistema artístico.

Los objetivos planteados con el Diplomado son:

- Objetivo General

- Mejorar el grado de capacitación en educación en artes visuales de los profesionales de la educación formal y no formal que trabajan en contextos de riesgo de exclusión social en el entorno periurbano de Tegucigalpa.

- Objetivos Específicos

- Dotar a los docentes que trabajan en situaciones de riesgo de exclusión social de formación especializada en artes visuales, y ayudarles a comprender, respetar, estimular y acompañar competentemente el desarrollo de la creatividad artística del alumnado.

- Cuestionar las teorías previas sobre la educación en artes visuales y capacitar al profesorado para profundizar críticamente en las propuestas de la legislación educativa hondureña respecto de la educación artística visual adoptando una actitud abierta y reflexiva respecto de las artes visuales y sus producciones y procedimientos contemporáneos.

- Promover estrategias de acceso a la cultura y el patrimonio de las personas en situación de riesgo de exclusión social, desarrollando formas de pensamiento que promuevan la construcción crítica de la identidad cultural.

- Facilitar a los profesionales del ámbito educativo estrategias y habilidades de intervención para que las artes visuales se puedan convertir en protagonistas de la acción social en prevención, integración, inclusión y formación profesional, promoviendo una actualización metodológica de los profesionales de la educación en métodos creativos de enseñanza, profundizando en modelos metodológicos de enseñanza basados en las artes e inclusivos y con capacidad de adaptación del Currículo al alumnado con necesidades educativas especiales.

- Desarrollar, diseñar e implementar programas, materiales, instrumentos y estrategias de enseñanza y evaluación para superar situaciones que dificultan la tarea del docente en dichos contextos: dificultades de aprendizaje, entornos familiares desestructurados, ambiente desfavorable, desnutrición, falta de formación inicial, carencia de materiales, discapacidad, etc. 
A lo largo de 4 años, el Diplomado EAV ha tenido graduados de distintos campos de especialización afines al ámbito de competencia (Tabla 2).

Tabla 2: Estadística de graduados del diplomado Enseñanza de las Artes Visuales en contextos de riesgo de exclusión social. UNAH. Fuente: Elaboración propia.

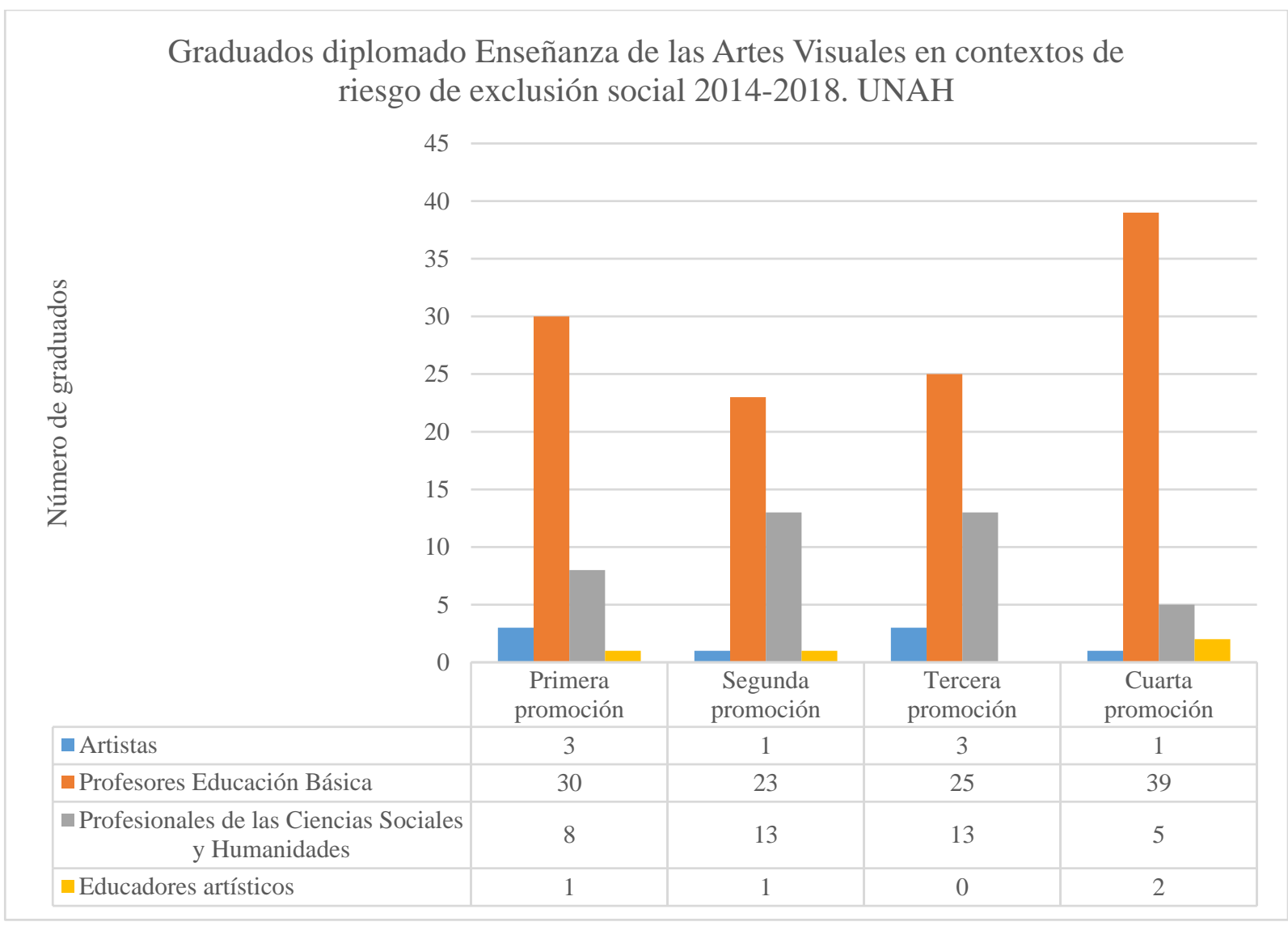

Y alcanzado los siguientes logros:

1. Las valoraciones cualitativas de cada promoción expresan una alta puntuación respecto al diplomado EAV.

2. El seguimiento a los graduados demuestra que la formación recibida ha afectado positivamente los sitios donde laboran: Proyecto Miqueas, Instituto hondureño de Antropología e Historia (IHAH); Dirección de comunicación, Periódico Presencia Universitaria, Dirección Ejecutiva de Gestión Tecnológica, Vicerrectoría de Orientación estudiantil (VOAE) y el CAC del UNAH; universidades privadas (Universidad Tecnológica Centroamericana, Universidad José Cecilio del Valle), centros de educación básica y media, editoriales, Juan A Leclerc (Escuela psicopedagógica), Proyecto Victoria (centro de rehabilitación), centro de educación especial, centros culturales, etc.

3. Se ha trabajado en cuatro centros educativos de ACOES, dos en Comayagüela, y uno aledaño a la UNAH.

4. Se tiene un total de 168 graduados. 
5. Se firmó un convenio específico de Vinculación Universidad Sociedad con ACOES y un convenio marco con la UGR.

6. Este proyecto fortaleció estratégicamente a las nuevas carreras artísticas (en proceso de diseño) especialmente a las Artes Visuales, el Diseño de objetos e innovación, la Gestión cultural y el Diseño gráfico, captando y formando a futuros aspirantes.

7. La experiencia del diplomado fue compartida en el curso en el Máster de Artes Visuales, un enfoque construccionista de la UGR.

\subsection{Las Metodologías Artísticas de Enseñanza en el diplomado EAV en contextos de riesgo de exclusión social}

Para ejemplificar la metodología empleada en la enseñanza del diplomado se sistematizó una práctica basada en las MAE: Juegos tradicionales, perfomance de Jorge Oquelí, de la siguiente manera:

1. Se inició identificando a artistas nacionales contemporáneos. Se eligió a Jorge Oquelí, artista visual del performance.

2. Después de visualizar varias de sus obras, se escogió la obra "Juegos Tradicionales"

3. Se procedió a realizar una entrevista personal para conversar sobre la obra elegida, fijando la atención en las fases de creación que llevaron al artista a concretar su obra.

4. Después de ello se reinterpretó su obra en la clase empleando los objetos más parecidos posibles.

5. Se compiló la documentación fidedigna de los niños asesinados en el último año, con nombre, edad y fecha de defunción, y seleccionó a aquellos a quienes el artista enseñó mientras vivieron.

6. Se obtuvo el material necesario: costales, marcadores, y el escaneo de los dibujos de algunos de los niños asesinados para posteriormente ser proyectados.

7. Se organizó el proceso en el aula: proyección del performance del artista visual (Figura 9), repartición de los datos de los niños a los estudiantes del diplomado, entrega de material para proceder a rotular los costales con un dato en cada costal (Figura 10), invitación a los participantes entrar a los costales, visualización de los dibujos de los niños asesinados (Figura 11), y luego, al salir de los costales, el docente propuso crear una historia diferente para ese niño asesinado. 
Figura 9. Iniciando las MAE a partir de la obra de Oquelí.

[Fotografía de Lidia Cálix].

(Palacio de los Deportes, UNAH.

2015). Archivos fotográficos

propios.

Figura10. En pleno proceso MAE de la obra de Oquelí.

[Fotografía de Lidia Cálix].

(Palacio de los Deportes,

UNAH. 2015). Archivos fotográficos propios
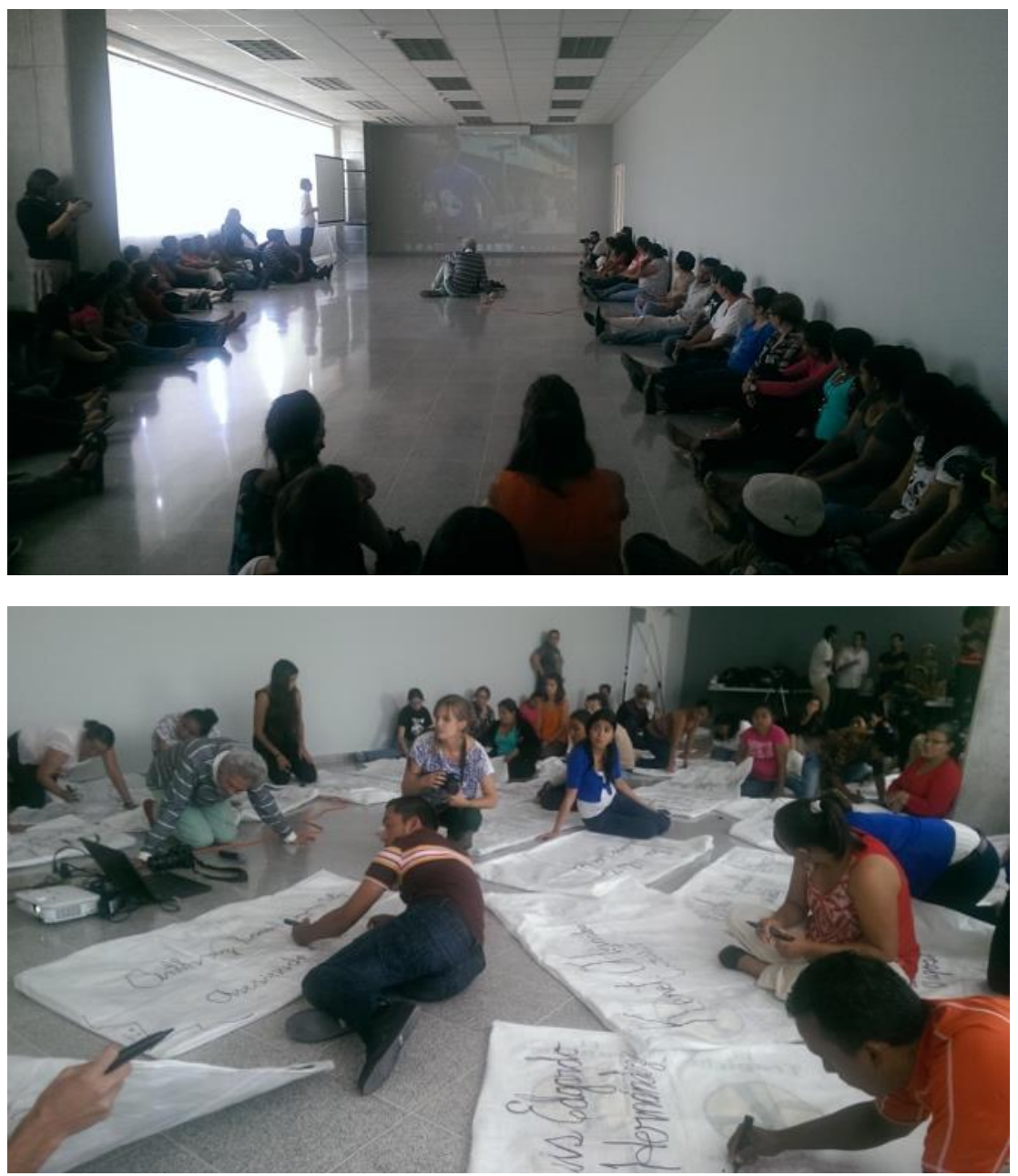

Figura 11. Finalizando las MAE con la obra de Oquelí.

[Fotografía de Lidia Cálix] (Palacio de los Deportes, UNAH. 2015). Archivos fotográficos propios.

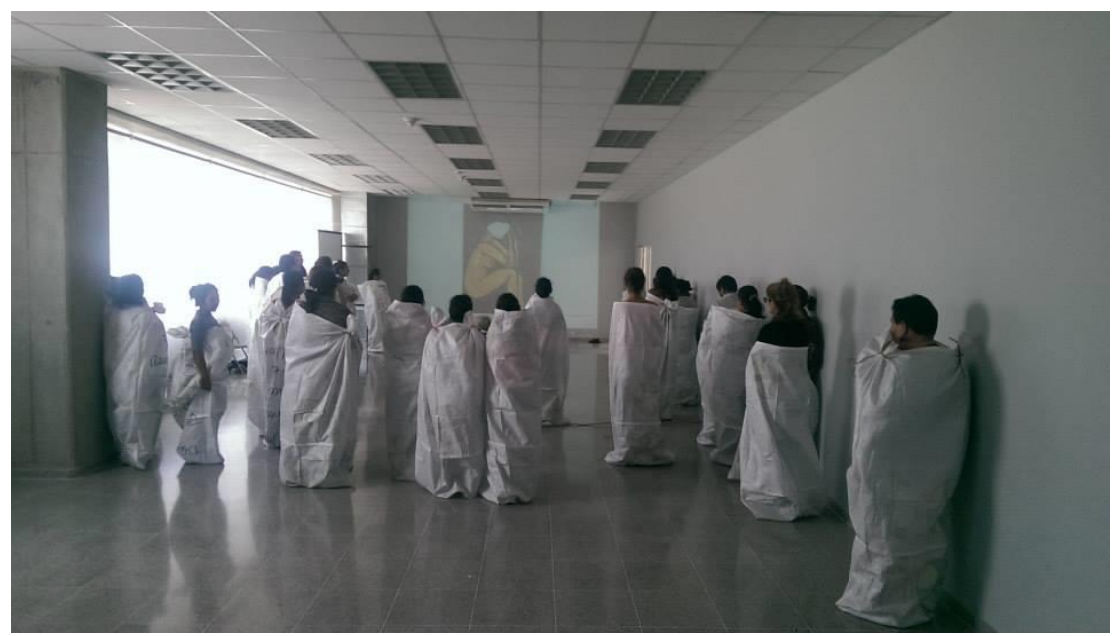




\section{Conclusión}

"Ante la injusticia imperante, crecí deseando otro mundo posible para mi país".

Lidia Cálix

Se tiene la convicción que la cultura y el arte son alternativas eficaces de intervención para la inclusión y la transformación social. Se afirma esto, con base en las evaluaciones de los profesionales beneficiados, observación de clases y los alcances del tipo de mediación. Quizás, el modelo de desarrollo economicista impide de algún modo valorar el bienestar que provoca a corto plazo la experiencia estética y las prácticas creativas con enfoque crítico. Pero la alegría, la ilusión, el asombro, la confianza, o bien, su extrapolación a otros ámbitos de la psique social para la resolución de problemas y vivencia de acciones colaborativas contrarrestan el espíritu del capitalismo salvaje: el individualismo.

Es preciso hacer pausa y recobrar la conciencia de la unidad del género humano y convenir su desarrollo pese al tanatos que le embarga, siempre con la firme convicción de que los intercambios culturales, particularmente el arte en el marco de la mediación social, son como el boomerang que va y viene en este mundo de favores infinito.

\section{REFERENCIAS BIBLIOGRÁFICAS}

Asociación para una sociedad más justa (2018, febrero 21). Honduras cae en índice de percepción de corrupción 2017 de Transparencia internacional. asjhonduras.com. Recuerpado de: http://asjhonduras.com/webhn/honduras-cae-en-indice-depercepcion-de-corrupcion-2017-de-transparencia-internacional/

CCETegucigalpa (2015, julio, 23). Museo del Prado en Honduras 2015 (Archivo de vídeo). Recuperado de: https://www.youtube.com/watch?v=Akfjca-A_C8

Confidencial HN (2016, diciembre, 16). Oficina anticorrupción "halla" 400 millones del magarrobo al IHSS. confidencialhn.com. Recuperado de: https://confidencialhn.com/2016/12/08/oficina-anticorrupcion-halla-400-millones-delempiras-del-megafraude-al-ihss/

CPTRTHonduras (2012, agosto, 15). Teatro del Oprimido (Archivo de vídeo). Recuperado de: https://www.youtube.com/watch? $=\mathrm{f} 3 \mathrm{k} 0 \mathrm{PA} 5 \mathrm{dmBw}$

Diario El Mundo. Internacionales (2018, marzo, 19). 49\% de jóvenes se quieren ir de Centromérica. elmundo.sv. Recuperado de: http://elmundo.sv/49-de-jovenes-sequieren-ir-de-centroamerica/

Diario Oficial La Gaceta (2018, enero 23). lagaceta.hn. Recuperado de: http://lagaceta.hn/

Presupuesto General de Ingresos y Egresos de la República y la Normas de Ejeución Presupuestarias. congresonacional.hn. Recuperado de: congresonacional.hn > uploads > 2017/11 > Disposiciones-201 
Dirección de Educación Superior. Portal UNAH (2017, septiembre,13). Estadísticas. des.unah.edu.hn. Recuperado de: https://des.unah.edu.hn/

Eisner, E. (1995). Educar la visión artística. Barcelona: Edit. Paidós.

El Heraldo (2014, abril, 07) País.Violencia por narcotráfico en Honduras "alcanza niveles alarmantes", según informe de la ONU. elheraldo.hn. Recuperado de: http://www.elheraldo.hn/pais/569264-214/violencia-por-narcotrafico-en-hondurasalcanza-niveles-alarmantes-segun-informe-de-la

El Heraldo. Honduras (208, febrero, 15). En 45 días han deportado a 666 menores hondureños. laprensa.hn. Recuperado de: http://www.laprensa.hn/honduras/1152617410/ni\%C3\%B1os-menos-deportados-eeuu-mexico-hondure\%C3\%B1os-

El Orden Mundial. Juan Pérez (2014, febrero, 5). Centroamérica el camino de la droga. el ordenmundial.com. Recuperado de: https://elordenmundial.com/2014/02/05/el-caminode-la-droga/

El País (2014, septiembre, 18). Latinoamérica tiene hambre de cultura. elpais.com. Recuperado de: https://elpais.com/cultura/2014/09/17/actualidad/1410981112_655895.html

El País. José Meléndez (2017, febrero,1). Más de 120 ecologistas han sido asesinados en Honduras desde 2010. elpais.com Recuperado de: https://elpais.com/internacional/2017/01/31/america/1485900562_925453.html

Expansión (s.f.). Índice de Paz Global. Datosmacro.expansion.com. Recuperado de: https://www.datosmacro.com/demografia/indice-paz-global

FOSDEH. (2017, noviembre, 14). Ilusionismo y disminución de la deuda pública. fosdeh.com. Recuperado de: http://www.fosdeh.com/2017/11/ilusionismo-disminucion-la-deudapublica/

Hipantv. Nexo Latino (2017, diciembre, 12). Opositores presentan en Honduras "pruebas" del fraude electoral. hispantv.com. Recuperado de: https://www.hispantv.com/noticias/honduras/362330/salvador-nasralla-presentapruebas-fraude-elecciones-presidenciales

Instituto Nacional de Estadística (2016, julio, 4) Boletín Educación Junio 2016. ine.gob.hn. Recuperado de: http://www.ine.gob.hn/index.php/25-publicaciones-ine/90analfabetismo.html

La Prensa. Honduras (2018, enero, 24). Maccih denuncia pacto de impunidad en el Congreso Nacional para blindar la corrupción. laprensa.hn. Recuperado de: http://www.laprensa.hn/honduras/1146210-410/maccih-denuncia-pacto-impunidadcongreso-blindar-corrupcion

Moreno, Ascensión (2016). La mediación artística: Arte para la transformación social, la inclusión social y el trabajo comunitario. Barcelona: Octaedro Editorial.

Nacion.com (2015, junio, 3). Política. Presidente de Honduras admite desvío de fondos públicos para su partido. nacion.com. Recuperado de: https://www.nacion.com/el- 
mundo/politica/presidente-de-honduras-admite-desvio-de-fondos-publicos-para-supartido/EHAYJIDYMJHM7J6TWRWLQEWFLU/story/

Noticias Honduras Hn. Primer diario digital (207, abril 19). Subempleo en Honduras supera el 50 por ciento. noticiashondurashn.com. Recuperado de: http://www.noticiashondurashn.com/?p=10070

Organización Interancional del Trabajo (s.f.). C169-Convenio sobre pueblos indígenas y tribales, $1989 \quad$ (núm.169). ilo.org. Recuperado de: http://www.ilo.org/dyn/normlex/es/f?p=NORMLEXPUB:12100:0::NO::P12100_ILO_C ODE:C169

Organización Internacional del Trabajo (2017, diciembre, 18). Panorama Laboral 2017. Amércia Latina $y$ el Caribe. ilo.org. Recuperado de: http://www.ilo.org/americas/publicaciones/WCMS_613957/lang--es/index.htm

Primicia Honduras. Periodismo y actualidad (2017, diciembre 22). Fosdeh: El 2017 ciera con más de 300 mil nuevos pobres en Honduras. primiciahonduras.hn. Recuperado de: http://www.primiciahonduras.hn/2017-nuevos-pobres-en-honduras/

Programa de las Naciones Unidas (2017, marzo, 21) "Desarrollo humano para todas las personas" Informe sobre Desarrollo Humano 2016 del PNUD. Hn.undp.org. Recuperado http://www.hn.undp.org/content/honduras/es/home/presscenter/pressreleases/2017/0 3/21/-desarrollo-humano-para-todas-las-personas-informe-sobre-desarrollo-humano2016-del pnud.html

Radio Progreso, la voz que está con vos (2017, julio, 28). Exigen cancelación definitiva de proyecto hidroelécrico Agua Zarca. radioprogresohn.net. Recuperado de: http://radioprogresohn.net/index.php/comunicaciones/noticias/item/3788-exigiendocancelaci $\%$ C3\%B3n-definitiva-de-proyecto-hidroel\%C3\%A9ctrico-agua-zarca

Teatromemorias (2016, noviembre, 02). Casa del teatro Memorias en Acción (Archivo de vídeo). Recuperado de: https://www.youtube.com/watch?v=8tJDt1k8jNM

The Goldman Environmental Prize (2019). About the prize. goldmanprize.org. Recuperado de: https://www.goldmanprize.org/about/

The Washington Post (2018, enero,12). Trump derides protections for immigrants from "shithole" countries. noticiashondurashn.com. Recuperado de: https://www.washingtonpost.com/politics/trump-attacks-protections-for-immigrantsfrom-shithole-countries-in-oval-office-meeting/2018/01/11/bfc0725c-f711-11e7-91af31ac729add94_story.html?noredirect=on\&utm_term=.f523d6402385 